\title{
LA CASA BÚNKER Y LA DECONSTRUCCIÓN DE LA CIUDAD
}

\author{
Alicia Lindón
}

Resumen: En este trabajo se analiza la deconstrucción de la ciudad en el contexto del proceso de suburbanización o expansión metropolitana. No es una deconstrucción material, sino de la vida social y simbólica que se desarrolla en sus formas espaciales.

En una primera parte se observan las formas de comprender la expansión metropolitana a partir de los modelos "americanos" de la ciudad dispersa y de los "latinoamericanos", como el de la fragmentación metropolitana.

En la segunda parte se analiza un aspecto esencial de la expansión metropolitana: la entronización de la casa, entendida como una resemantización de la noción "casa" y también como una transformación material de la misma. La tercera y última parte muestra la paradoja: la entronización de la casa ocurrida por la expansión de la ciudad termina deconstruyendo la ciudad.

Palabras clave: deconstrucción de la ciudad, suburbanización, fragmentación metropolitana, entronización de la casa, casa búnker.

Alicia Lindón, profesora-investigadora del Departamento de Sociología de la Universidad Autónoma Metropolitana, Iztapalapa, área de investigación: Espacio y Sociedad, y profesora de las licenciaturas en geografia humana y en sociología de la UAM-Iztapalapa y del posgrado en Estudios Sociales. Miembro del Sistema Nacional de Investigadores, nivel 2. Correo electrónico: alindon@prodigy.net.mx.
Abstract: This paper analyzes the city's deconstruction in the context of the suburbanization process or metropolitan expansion. The deconstruction is not material, but related with the social and symbolic life developed in its spatial forms.

In a first part, are reviewed the ways of understanding the metropolitan expansion, through the "American" models of dispersed city and the more "Latin-American" one's, as the one concerned with metropolitan fragmentation.

In the second part, a central aspect of the metropolitan expansion is analyzed: the enthronisation of the home understood as a resemantization of the home notion and also as a material transformation of itself. The third and last part shows the paradox: the enthronization of the home generated by the city's expansion, is ending as a city's deconstruction.

Key words: city's deconstruction, suburbanization, metropolitan fragmentation, home's enthronization, bunker's home.

S i hay un fenómeno extensamente conocido, al extremo de considerarse una trivialidad o un hecho dado, un verdadero taken for granted, es que a lo largo de la historia de la humanidad la aglomeración de viviendas ha sido el germen de las ciudades. Incluso, en tiempos recientes, y en nuestras ciudades latinoamericanas y mexicanas en particular, esto también se ha constatado una y otra vez en un proceso muy conocido como es la expansión de las 
grandes ciudades sobre sus periferias: La periferización o suburbanización. ${ }^{1}$ En esta última perspectiva, el ancestral fenómeno volvió a cobrar interés desde el punto de vista de la generación de mercados de suelo irregulares, autoconstrucción de vivienda por parte de los sectores más desfavorecidos, o bien en torno a la constitución de suburbios y barrios cerrados por parte de clases medias y medias-altas. Así, al estudiar cómo se conforma la ciudad se ha ido sustituyendo el interrogante sobre su origen - actualmente un tema casi anecdótico de historia de las ciudades - por otros de vigencia manifiesta: ¿cómo se extienden y reconstruyen las ciudades? y ¿cómo en ellas se configura la vida urbana? Las respuestas, por variadas que sean, siempre tienen relación con los procesos mencionados, a veces denominados "suburbanización" y otras veces conocidos como "periferización", por emplear los conceptos más usuales, aun sin negar otros.

Es muy relevante que en todos estos casos no se cuestione ni se someta a una reflexión más profunda la idea, aparentemente trivial, de que la aglomeración de más y más viviendas — sean de pobres, de clases medias o verdaderas expresiones del despliegue de la riqueza - es la forma de "hacer la ciudad". Por eso esta idea puede entenderse como un taken for granted en el sentido fenomenológico de la expresión. Los fenomenólogos que estudiaron el problema de los presupuestos, lo dado, tanto en la vida cotidiana como en el pensamiento científico - porque éste reproduce mecanismos de la vida cotidiana-, han mostrado que la fuerza de esos presupuestos está en que no se revisan, sólo se aceptan. Es precisamente la idea de que las casas hacen la ciudad la que sometemos a examen, más aún, ponemos de manifiesto que en algunas circunstancias actuales que parecen marcar un horizonte de futuro que no se debería soslayar, las casas - aun aglomeradas - deconstruyen la ciudad, es decir, navegan a contracorriente de lo que conocemos como la ciudad y la vida urbana.
La deconstrucción de la ciudad, sin duda, no se produce en el sentido material, sino en cuanto a la vida social y simbólica: la vida urbana se encuentra imbricada en las formas espaciales. Como dice Pesci, de la vida asociativa de la ciudad se pasa a la vida disociativa o disociada (1985); es decir, se recrea una suma de individualismos que compiten entre sí y desconfían unos de otros. Este proceso en ciernes no se observa en la morfología urbana, al menos no de forma evidente. Tampoco se puede apreciar sobrevolando estos territorios. La fotografía aérea sólo muestra la creciente expansión de la ciudad por sus bordes; esto es, lo ya conocido pero más extenso. Para darle visibilidad, y hacer inteligible esa deconstrucción de la ciudad, es necesario cambiar la escala, realizar un acercamiento al fenómeno observado y buscar el punto de vista del habitante. Este es el tema central del presente trabajo y es parte del interés creciente por estudiar los espacios domésticos en tanto espacios vividos (Collignon y Staszak, 2003), pero considerando que lo definido por Oriol Nel.lo como "la no ciudad" o "la ciudad sin confines" (1998), y por Rubén Pesci como la "ciudad in-urbana" (1985), constituye el contexto de sentido clave de esos espacios domésticos.

Con base en este tipo de interrogantes e hipótesis, este trabajo en una primera parte repasa brevemente las formas de acercarse a esta problemática de la expansión metropolitana a partir de los modelos "americanizantes" de la ciudad dispersa y los más "latinoamericanos" de la fragmentación metropolitana, ya que ambos modelos discuten un proceso donde toma sentido lo que denominamos "la entronización de la casa"; fenómeno que se analiza en la segunda parte y que supone una resemantización de la noción "casa", pero también una transformación material de la misma. Luego se avanza en el planteamiento de la deconstrucción de la ciudad por la entronización de la casa, para terminar con algunas reflexiones finales. ${ }^{2}$ 


\section{Entre la fragmentación y la ciudad dispersa/difusa}

Tanto la suburbanización como la periferización refieren fenómenos que ocurren en los confines de la ciudad, pero ésta no sólo se sigue construyendo — socio-simbólica y materialmente- en esas zonas, también se reconstruye en su interior, ya sea en los centros como también en lo que se ha denominado "zonas intermedias". Esa reconstrucción de las áreas centrales o intermedias casi nunca es ajena a lo que ocurre en los márgenes o bordes de la ciudad. En este sentido nos referiremos a los procesos de suburbanización y periferización como parte de la dinámica urbana en conjunto, y no como fenómenos que se agotan en sí mismos y en localizaciones circundantes a la ciudad, sino que involucran a toda la ciudad, particularmente por la difusión de modos de vida e imaginarios urbanos que llevan consigo.

En esos territorios llamados suburbios y periferias, que se extienden alrededor de las ciudades, la localización de más y más viviendas ha sido la clave para que en un momento dado terminen por considerarse parte de la ciudad misma, en un proceso entendido en términos de avance de la frontera urbana. Esto ha sido analizado desde diversas lecturas urbanas, incluso ha llevado a extensos debates y propuestas de medición — casi siempre insatisfactorios - respecto a los "supuestos límites de la ciudad".

En unos casos, ese avance de lo urbano sobre los territorios colindantes ocurre a través de la urbanización de tierras antes vacías; y en otros, ello alterna con la “anexión" de antiguos poblados. Desde nuestra perspectiva, este fenómeno se puede entender —al menos en apariencia - como "la casa que construye la ciudad", o dicho en otros términos, la construcción de la ciudad a partir de la casa. Tanto en el caso de la ocupación de extensas tierras vacías previamente, como en la incorporación de antiguos poblados en el ámbito urbano, el mecanismo de base es el mismo: En el vacío urbano - en un caso extenso y en otro intersticial — se van construyendo nuevas viviendas, haciéndose progresivamente más próximas unas de otras. Esas proximidades devienen en la base para la construcción de la ciudad como un todo diferente a la suma de las partes. Como dijera Sylvia Ostrowetsky, "la ciudad es más que la suma de los hogares que la componen” (2001: 145). Esto se debe a que la densificación va generando lo colectivo, lo asociativo y lo público, en términos sociales y territoriales, porque "la ciudad representa un particular tipo de vínculo entre desconocidos" (Ostrowetsky, 2001: 19). Indudablemente, en muchos casos, esas localizaciones crecientemente más densas no corresponden sólo a viviendas en el sentido habitacional, sino a construcciones destinadas a otros usos, por ejemplo, industrias.

El fenómeno de la suburbanización/periferización ha sido analizado en las últimas dos décadas por los urbanistas y estudiosos de la ciudad en general a través de varias interpretaciones. Nos interesa destacar dos tipos de modelos muy conocidos sobre estos procesos. Ciertamente, no estamos intentando revisar todos los enfoques y aportes sobre el tema, eso sería una obra en sí misma ya que es muy extensa la literatura producida en los diversos países. Sólo estamos tomando dos modelos teóricos muy difundidos, en principio opuestos, para recuperar de cada uno algunas ideas claves.

Estos procesos se empezaron a estudiar con particular interés en Estados Unidos desde los años setenta, primero bajo la expresión acuñada por Brian Berry (1976) de "contraurbanización", con la cual este geógrafo americano irlandés planteó que se había iniciado un proceso inverso a la urbanización. En vez de aquel proceso en el que los habitantes del campo se trasladaban a la ciudad, los urbanitas empezaban a desplazar su residencia hacia las afueras, generando extensas áreas suburbanas. Históricamente era lo opuesto a lo conocido hasta entonces. Años después, destacados analistas europeos de la ciudad se sumergieron en esa reflexión. 
Ya en los años ochenta, los analistas de estos procesos en las ciudades americanas y "americanizadas" observaban que la suburbanización había transitado hacia otra etapa: lo que experimentaban muchas ciudades americanas parecía desbordar a la conocida suburbanización, incluida la contraurbanización. Era algo distinto a un nuevo desplazamiento de la frontera urbana. Ante esas condiciones surge el neologismo Edge Cities, junto con otras expresiones emparentadas — ciudad difusa, ciudad dispersa...- - para dar cuenta de los grandes complejos que han crecido, ahora en los márgenes de los suburbios de las ciudades americanas. El conocido neologismo introducido por Joel Garreau (1991), Edge Cities, tuvo su arquetipo inicialmente en Tysons Corner, suburbio situado al oeste de Washington, en Virginia.

En las Edge Cities, uno de cuyos rasgos característicos es que se desarrollaron en la intersección de las autopistas más importantes, los habitantes de los suburbios encontraron centros comerciales, escuelas, hospitales e incluso aeropuertos regionales y fuentes de trabajo, ya que suelen ser localizaciones muy atractivas para las corporaciones, que instalan allí sus oficinas. También se ha constatado que en estos nuevos territorios periféricos — "la periferia de los suburbios" — se ha dado un progresivo aumento de la criminalidad, así como de los congestionamientos viales, es decir, se incrementaron algunos de los males de la metrópoli, de los cuales supuestamente se huía (Garreau, 1991). Estos lugares también están fuertemente marcados en términos de segregación social y el sentido de comunidad es aun más débil que en el suburbio tradicional, en donde ya era superficial.

Este fenómeno ha sido particularmente prolífico en cuanto a los neologismos que ha permitido acuñar en el ámbito de los estudios urbanos. ${ }^{3}$ Por ejemplo, para Edward Soja (2004), la expresión "exópolis" es la que mejor da cuenta de estas formas metropolitanas. También han participado activamente en esta reflexión algunos pensadores europeos (por ejemplo, italianos), alcanzando en muchos momentos un papel destacado, como el de Giuseppe Dematteis (1995), ${ }^{4}$ con su planteamiento de la "ciudad "difusa", o Stéfano Boeri (1993). ${ }^{5}$ Muy escuetamente se puede señalar que el concepto de "ciudad difusa" se refiere a un momento histórico, aquél en el que las redes se extienden por el territorio, haciendo que todo sea urbano. Finalmente, se puede recordar que en cierta forma esto había sido anticipado por Lefebvre, cuando en los años sesenta planteaba que la superficie entera del planeta se urbanizaría. Otros autores fueron introduciendo matices y neologismos. Por ejemplo, Veltz (1999) recurrió a la metáfora de los "archipiélagos urbanos".

Toda esta reflexión no ha sido ajena al análisis de las ciudades latinoamericanas. A pesar de ello hay que reconocer que en éstas se han desarrollado otros modelos, que aun cuando convergen en la perspectiva de lo fragmentado, tienen otros matices. Ha predominado el énfasis en la "fragmentación metropolitana", o la "metrópoli fragmentada", para utilizar la expresión del geógrafo brasileño Milton Santos (1990). Para esta perspectiva, la idea de la fragmentación se funda en la inmovilidad de los pobres en ciertas zonas de la metrópoli; esto lleva a la constitución de un tipo de habitante metropolitano que Santos llamó "los prisioneros del espacio local" (1990: 89). Para los residentes de estas periferias pobres, la limitación en el acceso a la metrópolis implica no sólo el desarrollo de actividades laborales en el medio local —usualmente precarias - sino también la inaccesibilidad a todo lo que ofrecen otras zonas de la ciudad; y en última instancia, la falta de acceso a la ciudad misma.

En otra ocasión, se ha puesto de manifiesto que en este tipo de periferias la precariedad no sólo es laboral, también se da en el modo de "habitar" como una condición holística, que conlleva una precariedad familiar y vecinal prolongada a lo largo de las trayectorias de vida. Esto es lo que permite postular una "precariedad de vida" en sentido amplio (Lindón, 2003). 
En otros casos se ha destacado el mismo tipo de exclusión, pero articulado con la realización de grandes desplazamientos cotidianos entre el lugar de trabajo y el lugar de residencia dentro del área metropolitana. En este último sentido se planteó que el desplazamiento en sí implicaba una "expoliación" adicional de esta fuerza de trabajo (Kowarick, 1994).

De cierta manera, estos dos tipos de interpretaciones indirectamente expresan la deconstrucción de la ciudad concentrada y compacta del siglo xx y la construcción de una ciudad diferente a la conocida, con creciente fragmentación y dispersión en cuanto a la morfología urbana. Estos modelos hablan de la ciudad desconcentrada, segregada en términos sociales y con diversas formas de exclusión social. Seguramente, nuestro trabajo se suma a estas visiones comentadas, aunque busca acercarse al fenómeno desde un ángulo poco estudiado: el sentido del lugar y la subjetividad espacial en torno a la casa y lo externo a ella. En buena medida este ángulo de observación se relaciona con nuestra meta de no encajonar el análisis en el ámbito de la morfología urbana, como ha sido uno de los énfasis de las aproximaciones comentadas, ni tampoco dejarlo en la consideración de los flujos pendulares de la población, otro sesgo frecuente.

En suma, estas interpretaciones usuales se construyen a partir del análisis de la dispersión, la fragmentación y las nuevas fronteras en su dimensión material, tanto en lo que respecta a la construcción física del espacio urbano - morfología urbana - como en referencia a los procesos económicos ligados a esa construcción material del espacio, y también en lo relativo a los movimientos de la población — los flujos pendulares y no pendulares- - Respecto a la morfología urbana dispersa, por ejemplo, se ha analizado la formación de guetos y áreas más o menos cerradas dentro de la ciudad. Esto indica, en muchas ocasiones, que estos análisis han avanzado más allá de las formas materiales, explorando aspectos sociales como la segregación urbana o la exclusión social. Pero aun así, incluyendo aspectos sociales, se ha tendido a observar el fenómeno "desde arriba" y "desde afuera". Este tipo de miradas son parte de lo que en otras ocasiones hemos denominado enfoques "exocéntricos", es decir, desde la entera visión del analista (Hiernaux y Lindón, 2004b), independientemente de que el especialista enfatice una u otra dimensión.

Los análisis sobre los suburbios de las ciudades americanas en sus diversas versiones - ya sean los primeros centrados en el proceso de suburbanización, o los posteriores dedicados a las periferias conocidas como Edge Cities - mostraron el papel de las clases medias acomodadas, y a veces de las clases altas, en la producción de la riqueza y su expresión territorial: la construcción de estos territorios periféricos. En cambio, en el caso de los modelos analíticos desarrollados desde las ciudades latinoamericanas, la problemática de las periferias casi siempre remite a las condiciones miserables de los pobres y marginales de la metrópoli. Sin por ello negar que, en los últimos años, las investigaciones latinoamericanas también se han interesado en los barrios cerrados periféricos de grupos medios (Cabrales, 2002). Indudablemente, en ambos casos esos sesgos no son arbitrariedades de los estudiosos de la ciudad, sino referencias directas a las situaciones empíricas.

Nuestra interpretación del fenómeno metropolitano surge de las ciudades latinoamericanas, y mexicanas en particular, pero asumiendo que los modelos latinoamericanos de la pobreza y el aislamiento de las periferias — como los mencionados más arribaresultan insuficientes para entender plenamente la realidad actual, aunque no por ello dejan de ser iluminadores en muchos aspectos. Indudablemente, tampoco parece muy oportuno asumir que podríamos comprender la expansión de nuestras ciudades exclusivamente en términos de los modelos americanos, tipo Edge Cities. Por eso buscamos la mediación o 
triangulación entre ambas miradas. Esta decisión no se debe a la moda intelectual de las "triangulaciones" diversas — como garantía de amplitud intelectual—, sino que resulta de una condición particular que consideramos notoria en las ciudades mexicanas, aunque frecuentemente extendida a muchas otras ciudades latinoamericanas, como es su hibridación.

Estamos de acuerdo con que estas visiones latinoamericanas de la fragmentación, por las condiciones de aislamiento —a veces de inaccesibilidad- de los grupos sociales más pauperizados de las metrópolis, tienen un referente empírico insoslayable. Sin embargo, las ciudades mexicanas constituyen un ejemplo característico de la articulación, pero también hibridación, de ambos modelos en los modos de vida y los imaginarios urbanos: El carácter híbrido radica en que en ellas está presente la característica fragmentación en la pobreza metropolitana, pero también presentan huellas inconfundibles del modelo suburbano americano. Esta articulación se establece desde los imaginarios urbanos que están recibiendo y circulando constantemente imágenes del suburbio americano, del modo de vida americano, del "sueño americano", a través de los medios, pero también a través de las experiencias directas de los migrantes. Dichas imágenes son apropiadas, modeladas e incorporadas en la vida práctica.

Sin duda, la televisión y el cine $e^{6}$ han jugado - y lo siguen haciendo- un papel fundamental en la difusión y reconstrucción de estos imaginarios urbanos. Pero también se debe reconocer que otros medios han contribuido en el mismo sentido. Uno de ellos es el caso de las revistas de divulgación, que a través de imágenes fuertes indican cómo organizar y cómo configurar los espacios de la vida, incluso de la vida privada. Al respecto cabe recordar que destacados pensadores, como Henri Lefebvre (1984) y Erving Goffman (1991), en los años sesenta y setenta reflexionaron sobre las imágenes ricas en códigos sociales que presentaban ciertas revistas de divulgación de gran difusión. Recordemos que Lefebvre se interesó precisamente por imágenes de los espacios domésticos y sus entornos, publicadas en semanarios destinados sobre todo a las mujeres (1984: 109-110). Por su parte, Goffman orientó aquella investigación a las pautas de género que definen qué es lo femenino y que se encuentran encapsuladas en fotografías publicadas en revistas femeninas. En suma, las imágenes que circulan en los medios imponen sus colores y sus formas, sus estilos, homogeneizan los imaginarios urbanos, los colonizan, y así reducen la imaginación.

Esto es un fenómeno al que están expuestas no sólo las ciudades mexicanas y latinoamericanas, sino las de todo el mundo. En el caso de las ciudades mexicanas hay que tener en cuenta que lo anterior es retroalimentado constantemente por la información procedente de las experiencias migratorias. Tanto las imágenes que proceden de los medios como las que circulan por las experiencias migratorias directas construyen nexos - a veces de formas inesperadasentre algunos rasgos del modelo latinoamericano de periferia fragmentada, y a veces aislada en la pobreza, y el modelo del suburbio americano disperso, asociado con la casa individual, la familia nuclear y la vida tranquila, es decir, protegida de la aceleración propia de las grandes ciudades. Los promotores inmobiliarios también juegan un papel importante en la difusión del modelo americano (López Lévi et al., 2006), aun en la pobreza excluida, y le dan fuerza y permanencia renovada mediante las formas espaciales que construyen. Por ejemplo, los modelos básicos de vivienda de interés social contribuyen a reproducir aquel modo de vida.

Los medios de comunicación y los agentes inmobiliarios tienen una participación clave en la configuración del imaginario suburbano, pero también hay que reconocer que las clases medias tienen por igual un papel nada despreciable en la cuestión. Esto se debe 
a que son los grupos sociales de la ciudad más abiertos a las "innovaciones", con la particularidad de que en muchas ocasiones se trate de innovaciones "colonizadas". Las innovaciones casi siempre son retazos del modo de vida suburbano americano retomados en otros contextos. Esto no niega que la incorporación de una práctica o un objeto material en un contexto diferente a aquel del cual procede, lleve consigo una resignificación.

Si bien esta hibridación de rasgos característicos de ambos modelos suburbanos y periféricos se produce en el ámbito de los imaginarios urbanos, también tiene fuertes implicaciones en la producción material de la periferia metropolitana, de manera igualmente "híbrida". En ese sentido, aunque resulte paradójico, para comprender las metrópolis fragmentadas mexicanas, desde el punto de vista de sus propios habitantes, hay que revisar los análisis de los suburbios americanos, no para buscar réplicas exactas, pero sí para preguntarnos cómo se resemantizan en los distintos contextos y, sobre todo, qué ha ocurrido con la casa en estos modelos suburbanos híbridos, por qué ha adquirido una centralidad tal.

\section{La "entronización" de la casa}

La ciudad difusa o dispersa también se aproxima a la idea de archipiélago, donde lo que separa a cada parte (es decir, a cada isla) es el mar, y al mismo tiempo es lo que conecta a las partes y permite construir la idea de un particular todo: "el archipiélago". En el conjunto metropolitano difuso y disperso ocurre algo semejante, pero también algo diferente: en vez de islas encontramos casas, con la particularidad de que cada vez se desdibuja más la trama social entre ellas, sobre todo desde la perspectiva del vecindario. Paralelamente a ello, los habitantes configuran las casas cada vez más como "nodos" fuertes e independientes. Se produce un peculiar proceso de construcción socio-simbólica de la casa. Esto implica que aquella metropolización difusa y fragmentada, ya analizada, deviene en un "contexto" de sentido de un "texto" — la casa- que invita a descifrarlo; tarea difícil de emprender desde miradas exocéntricas (Hiernaux y Lindón, 2004b) preocupadas por el todo.

Si bien las casas están conectadas entre sí a través de redes de servicios diversos, esas redes sólo se pueden entender como una "trama" en la escala del territorio metropolitano extenso, la ciudad difusa. Pero si se observan con una óptica más próxima, se constata que estas conexiones no llegan a constituir una trama. En la escala próxima, lo que cobra relevancia es la casa en sí misma. Por ello, nuestra hipótesis rectora es que en las metrópolis dispersas y fragmentadas se asiste — sobre todo en los suburbios y periferias - a una entronización de la "casa" que replantea lo que es la ciudad. En otras palabras, las grandes ciudades actuales han llevado a redefinir el sentido de la casa, pero esa nueva concepción tiene implicaciones considerables en la ciudad misma.

Desde esta perspectiva, la expresión "vivienda" no es la más oportuna, por eso la sustituimos por la de "casa". . La vivienda es la construcción material, independientemente del sujeto que la habita. En tanto que la casa constituye ese espacio de vida primario del sujeto, cargado de sentidos, de memoria, sueños y fantasías. ${ }^{8}$ Esto implica que sería posible observar dos viviendas exactamente iguales en términos materiales, pero diferentes como casas por la forma de vivirlas y apropiarlas que han realizado los diferentes sujetos que las habitan y, en consecuencia, por la memoria diferente que aloja cada una de ellas. De ahí que ahora nos refiramos a la casa, dándole esta particular carga de sentido.

Al otorgarle centralidad analítica a la casa, conviene recordar que destacados autores han señalado que ésta representa el punto de referencia básico desde el cual el sujeto construye su relación con el entorno, es decir, con la colonia o el barrio, y en consecuencia con el 
vecindario, es decir, ese colectivo social que habita el barrio. Pero también es el punto de referencia con relación a lo que está más allá del barrio, es decir, la ciudad... La casa usualmente tiene el sentido de protección y abrigo. Bárbara Allen dice: "la casa es un lugar de síntesis, lugar último, lugar por el cual, aun en situaciones difíciles, las personas movilizan sus recursos y defensas para preservarlo" (2003: 140). Esta autora también plantea que en ocasiones el sentido de la casa se puede apreciar ante su "pérdida".

Según Bachelard, la "casa es nuestro rincón en el mundo". Es — se ha dicho con frecuencia - nuestro primer universo. "Es realmente un cosmos" (1992: 34). Constituye el primer mundo del ser humano, sustituye la contingencia; sin casa el ser humano estaría disperso. Este autor además apunta que "el estar amparado sensibiliza respecto a los límites del albergue" (1992: 35). Así, la imaginación puede construir muros con elementos tan volátiles como las sombras, y sentir protección dentro de esos "muros", construidos por ejemplo con sombras. Pero también muestra el autor que la imaginación puede reconstruir fuertes murallas en muros frágiles y vulnerables, llevando a su habitante a sentirse desprotegido aun detrás de la muralla. Por esta condición que asocia la casa a su habitante y a su existencia, la casa también lleva consigo una memoria. Pero es una memoria compleja, no sólo de lo vivido allí, sino también de lo que se ha vivido en otras casas, que entra en el juego de las analogías y contrastes permanentes que realiza todo sujeto en cualquier experiencia espacial. Al mismo tiempo, la protección de la casa hace que en ella por igual se incluya lo que su habitante proyecta en un horizonte futuro, y no sólo su pasado y presente.

En el contexto de fragmentación y dispersión de las ciudades mexicanas y, particularmente, de sus periferias, estas reflexiones pioneras sobre la casa - que en Bachelard es verdadera piedra fundamentalpareciera que requieren ser revisadas. La idea de la casa como el primer mundo o el primer universo parecería que transita de manera acelerada hacia una redefinición en términos de "nuestro mundo" o "nuestro universo". El primer mundo es una referencia al lugar básico y esencial desde donde nos conectamos con el mundo. En cambio, considerarla como "el mundo" es una expresión de cierre respecto a la socialidad en sentido amplio. Nuestra interpretación es que está dejando de ser "el primer mundo" para ser "nuestro mundo". Veamos a continuación varias dimensiones de ese proceso de resemantización, unas corresponden a la escala de la casa dentro del medio urbano y otras a la escala de la casa por dentro.

I. La casa patrimonio. El fenómeno cada vez más extendido de la urbanización no concentrada, o dispersa, también parecería ir acompañado de un nuevo sentido atribuido a la casa, que denominamos "patrimonialista". Este sentido lleva a concebir la casa como un "patrimonio" (Lindón, 2005a), es decir, un bien que se posee. Por un lado, es necesario reconocer que el patrimonialismo en términos generales parecería que cada día cobra mayor centralidad en las sociedades contemporáneas: es la búsqueda de un patrimonio, de posesiones. Pero dentro de los diversos bienes que pueden encarnar el patrimonialismo, la vivienda es uno de los que tiene mayor fuerza. No carece de sentido que a estos bienes se los denomine "raíces", más allá de la evidente referencia a la inmovilidad de esta palabra (la casa), también hay que subrayar que expresan una forma de anclaje de las personas en el territorio, al menos en la medida en que son habitados. Lo interesante es que en la cultura del patrimonialismo las raíces que da la casa son indisociables de su valor formal en el mercado.

Esta tendencia patrimonialista debería ser contextualizada en las sociedades del riesgo y de lo incierto, donde la posesión de una casa se suele vivir como una seguridad, cuando éstas parecen desvanecerse de manera acelerada. En otra ocasión también hemos 
planteado que dicho patrimonialismo es parte del tránsito del "ser al tener" que experimenta el individuo en la modernidad, incluso el tener llega a constituir una fuente de identidad. Cabe recordar a título de ejemplo que Henri Lefebvre, en su crítica a las modernas sociedades urbanas, comentaba en los años sesenta, las modas cíclicas y entre ellas hacía referencia a "la temporada de los llaveros" como un período en el cual se constituyó en una moda portarlos como signo indiscutible de la propiedad (1984: 136).

En suma, en el patrimonialismo se viene a plasmar un conjunto de aspectos relacionados con la historicidad, que terminan cristalizando en la construcción social de la noción de la "casa propia" como algo más denso y profundo que la propiedad en sentido jurídico. Es un mecanismo socio-simbólico en el cual algunos sujetos depositan la ilusión $-\mathrm{O}$ posibilidad - de obtener visibilidad social, integración social, resarcimiento y compensación por pérdidas o exclusiones antiguas (Lindón, 2005a).

II. La casa "equipada y aprovisionada". En este modelo suburbano, el habitante parece empujado a "refugiarse" en la casa, pero ello conlleva una concepción de la casa diferente a la del tradicional "refugio" que se podía hallar en otro tipo de medio urbano. La casa se va concibiendo con un equipamiento interno cada vez más diversificado, constituido por enseres, objetos e instrumentos diversos. La primera explicación de esto — notoriamente insatisfactoriase puede plantear como una articulación directa entre el consumo doméstico y la diversificación de la producción industrial de estos objetos. No obstante, consideramos que el problema es más complejo. Esto parece expresar patrones de consumo que reflejan una concepción particular de la casa, y por ello pueden ser funcionales para esa producción. Ese equipamiento interno de la casa responde a la concepción de que, en su interior, sus habitantes deben tener las condiciones materiales para resolver muchas actividades que anteriormente se resolvían en el medio urbano. Pero desde el momento en el que éste se vive como hostil y se trata de reducir la exposición al mismo, entonces el concepto de equipamiento interno de la casa tiene que ajustarse, ampliándose.

Ejemplos de ese equipamiento son todos los objetos domésticos vinculados con la informática, pero también la variedad de objetos electrodomésticos y herramientas domésticas diversas que permiten realizar dentro de la casa muchas tareas y actividades que antes requerían de los prestadores de servicios diversos y trabajadores especializados que ofrecía la ciudad. En suma, el equipamiento desplaza una serie de actividades cotidianas de la ciudad al interior de la casa, lo que termina siendo un debilitamiento de la vida urbana.

En este modelo suburbano la casa, asimismo, se concibe en la perspectiva del acopio de víveres. Eso que en otros tiempos se asociaba a circunstancias particulares, socialmente marcadas por alguna situación de pánico o extraordinaria, ahora se constituye en la pauta cotidiana. Esto tiene fuertes implicaciones tanto en la cotidianidad de sus habitantes, como en las formas materiales que debe reunir la casa para poder dar cabida a esta lógica del acopio de víveres. Así, los desplazamientos en el espacio urbano para resolver el aprovisionamiento se extienden en distancia física, pero se realizan dentro de ciclos de tiempo más extensos. Del ciclo de 24 horas, el aprovisionamiento ha pasado a períodos más extensos, como el semanal o quincenal. Estas temporalidades tienen implicaciones en las interacciones sociales, más aún si se considera que las formas de aprovisionamiento ya casi no requieren relaciones cara a cara entre el comprador y el vendedor, más bien son relaciones en las que el urbanita interactúa sólo con los objetos de consumo.

III. La casa protegida y cerrada. Por último, no se puede dejar de mencionar el equipamiento de la casa 
para la seguridad — como por ejemplo los diversos y difundidos sistemas de blindajes_ que también es objeto de sofisticación creciente y evidentemente de obsolescencia acelerada, al igual que los anteriores equipamientos. $\mathrm{Y}$ aún hay otra dimensión del equipamiento de la casa para la seguridad que es necesario comentar: todo aquél que aumenta la barrera que la separa del mundo exterior. En parte esto se materializa en los dispositivos diversos para la seguridad, sin embargo no se agota ahí. También hay recursos materiales que no dan seguridad literalmente pero marcan la separación de la casa con lo exterior. Un ejemplo emblemático son los denominados mecanismos de "insonorización"; además, existen los vidrios dobles, vidrios polarizados o los cierres herméticos de las aberturas de las casas. Es relevante que para el concepto de casa moderna propio de estas urbanizaciones que se americanizan, o al menos que lo buscan, la perspectiva de cerrar la casa de la manera más hermética respecto al exterior se torna un atributo central de alta valoración y estima social; aunque también tiene una fuerte carga simbólica. En síntesis, se han multiplicado los mecanismos y estrategias para constituir la casa, cada vez más, en un "espacio cerrado hacia el exterior". Esto es relevante si recordamos que durante mucho tiempo la casa era concebida como un refugio del habitante, pero articulada orgánicamente con la ciudad (Contamine, 1990).

El caso particular de los barrios cerrados sólo viene a implicar una doble frontera sobre el mismo fenómeno. Dicho en otros términos, el barrio cerrado no desplaza esa frontera entre lo interno a la casa y lo externo, a una distancia física mayor de la casa — es decir, al conjunto de viviendas donde se integra — sino que duplica la frontera porque en el interior de los barrios cerrados se mantienen estas separaciones herméticas de la casa respecto al medio circundante, sólo que luego se interpone una segunda frontera que separa al conjunto del barrio con el exterior.
De esta forma, el modelo de urbanización difusa pareciera estar cambiando el sentido ancestral de la casa como lugar de protección y refugio, la casa como el rincón en el mundo, a partir de su separación creciente respecto al exterior debido a que éste es concebido como hostil, peligroso y diferente. Pareciera que estamos frente a los contornos de una trama de sentido en la cual la casa es algo semejante a una fortaleza o bien un binker. Sin embargo, la historia urbana muestra que aun en las fortalezas de la Edad Media había socialidad en sentido amplio, ya que ésta era en sí misma una ciudad: la ciudad amurallada. En el modelo actual, el amurallamiento de la casa termina con la socialidad y orilla a sus habitantes a profundizar el repliegue en el sí mismo.

No obstante, cabe subrayar que tal repliegue no tiene nada de aquellos procesos que algunos pensadores de la primera mitad del siglo xx consideraban necesarios para el ser humano de la modernidad con el fin de alcanzar una conciencia profunda del mundo y de sí mismo. ${ }^{10}$ Estos repliegues del habitante en el interior de la casa en buena medida lo sumergen en el consumo de imágenes y objetos a los que puede acceder desde esa interioridad, en virtud de las redes que interconectan la casa. Así, la ciudad dispersa y fragmentada está configurando las condiciones para la construcción social de la casa búnker.

\section{Hacia la deconstrucción de la ciudad}

La casa bunker contribuye de muchas formas a la deconstrucción de la ciudad en tanto contacto imprevisto con el otro, experiencias de lo heterogéneo, lo inesperado y diverso. Pero tal deconstrucción no atenta contra las formas espaciales propias, sino contra las formas de apropiárselas y vivirlas. Sin duda, esta resemantización de la casa no lleva consigo la desaparición de las calles ni de otros espacios públicos, menos aun se destruyen las proximidades físicas entre casas. 
Dicha deconstrucción puede pasar inadvertida para quien no observe con detalle el fenómeno. Fácilmente se puede confundir con otros fenómenos entremezclados, como el anonimato o la centralidad del automóvil. De esta manera la deconstrucción resulta de la conjunción de varios sucesos, todos ellos potenciados por el papel de la casa búnker. Algunos de éstos son los siguientes:

a. Hostilidad del medio urbano. En este modelo suburbano, difuso y fragmentado, parecería que todo lo externo a la casa tiende a vivirse — a través de las imágenes suburbanas - como un medio hostil en varios sentidos. La hostilidad incluye inseguridad, desconfianza hacia el otro, no sólo por temor a la victimización sino también por el rechazo a la diferencia. La hostilidad además se refiere al sentido socialmente construido y extendido del rechazo a los espacios llenos, densos y abigarrados. En otra ocasión hemos analizado esta tendencia como el gusto por todo lo que ha sido condensado en la expresión Wilderness: ${ }^{11}$ lo natural, lo vacío, lo despoblado, el espacio "abierto" (Lindón, 2006b).

En esta construcción del medio urbano como hostil también se viene a integrar el "sentido del miedo" respecto al espacio, que se ha extendido considerablemente en las grandes ciudades tanto latinoamericanas en general como mexicanas en particular. El miedo no es lo mismo que la simple hostilidad, es una construcción de sentido más profundo que se materializa en los lugares y llega a generar conductas fóbicas, como las topofobias y agorafobias (Lindón, 2005b y 2006a). El sentido del miedo profundiza la reclusión en los espacios interiores, donde se experimenta cierta protección respecto a un entorno supuestamente peligroso, en buena medida porque se le percibe como el territorio apropiado por otros peligrosos, que siempre pueden acechar.

Esta visión del medio urbano como hostil contribuye para que la exposición a ese medio sea bajo la forma de apariciones rápidas, fugaces ${ }^{12} \mathrm{y}$, sobre todo, protegidas. En buena medida la exposición al medio urbano de manera protegida se concreta a través del automóvil, que conforma una barrera que aísla crecientemente del exterior y dentro de la cual el individuo reconstruye su mundo. Hace algunas décadas, Kevin Lynch (1998) se planteaba cómo era la ciudad del automovilista, en contraste con la del peatón. Hoy parecería que el automovilista no tiene frente a sí una ciudad, sino un espacio circulatorio inmediato. Esta situación ha sido profundizada por el trazado de autopistas intraurbanas y confinamientos vehiculares, que interponen diversas barreras visuales que bloquean la ciudad que se ve o que se podría ver, pero no se ve.

Por otra parte, los desplazamientos en el medio urbano — esas apariciones protegidas — se padecen y producen fatiga. Los desplazamientos dentro de la ciudad perdieron enteramente los dos sentidos que durante mucho tiempo tuvieron: tanto el sentido del viaje, de la exploración de un territorio desconocido, como el sentido del regreso a un territorio conocido. En sustitución de ellos, los desplazamientos toman el sentido de la fatiga.

Así, el habitar que se atribuía a la ciudad —las personas se consideraban habitantes de una ciudadse trasfiere al microespacio que constituye la casa: la casa se habita y la ciudad se circula. ${ }^{13}$ La hostilidad de la ciudad encierra a su habitante en la casa y en otros espacios obligados, como los de trabajo, educación, consumo, que de una forma u otra intentan recrear el espacio de la casa. Esto tiene implicaciones no poco relevantes ya que el "habitar la ciudad" llevaba consigo la socialidad. En cambio, cuando el espacio habitado es la casa se observa una reducción de la socialidad, como un proceso más complejo que el individualismo conocido. No sólo implica la reducción drástica en el número de personas con quienes se interactúa, sino que anula el vínculo social con desconocidos, propio de la vida urbana. Si a ello se agrega la tendencia -aún 
tenue, pero ya presente en las ciudades latinoamericanas- del hogar unipersonal, la socialidad resulta indudablemente alterada: al respecto se puede observar que Daniel Pinson y Sandra Thomann postulan el tránsito del "territorio grupal al territorio individual" (2001:109) para el caso de los suburbios y periferias del sur de Francia.

b. La segunda casa, la casa móvil. En este modelo suburbano, el automóvil particular es el recurso básico para reducir la exposición al medio hostil. Por ello, acaba constituyéndose como una caricatura de la casa; es la segunda casa. Asume algunos de sus atributos: cada vez más equipado y también cada vez más aislado del mundo exterior. El aislamiento del exterior no es sólo por el equipamiento de la "seguridad". También hay una desvinculación con lo externo que se expresa en dos planos: por un lado, la atención hacia el interior del automóvil, ya sea por los otros con quienes se comparte el espacio o, lo más frecuente, la atención prestada hacia los objetos diversos que forman parte de ese espacio dentro de un recinto. Por otro lado, la desvinculación con la exterioridad también se manifiesta en el desinterés por vivir el automóvil como se vivió en otra época, es decir como una ventana para ver el mundo.

Esta concepción se basa en que el campo visual desde el interior del automóvil es el inmediato requerido por la conducción. Y para quien no conduce el vehículo no hay nada externo que ver; en cambio puede haber diversas interioridades adicionadas que atraigan la atención. Un ejemplo de estos aditamentos son los lectores de DVD para vehículos. Con estos equipos se "transforma" el espacio interior del vehículo en una suerte de "sala de cine móvil", frecuentemente destinada a los niños pero no exclusivamente. El ejemplo reitera la característica antes comentada de que, para quienes circulan en un automóvil, "no hay" un espacio urbano que pueda ser observado, sólo hay otros vehículos próximos. c. Los espacios públicos circulatorios. Estos fenómenos que ocurren en relación con la casa también tienen otra connotación importante, como el vaciamiento de los mal llamados espacios públicos y su limitación a las funciones circulatorias. La calle como el espacio público por excelencia deviene, en este modelo, en un espacio del "pasar", y no del "estar ahí’. Tal situación ha sido extensamente documentada en diversas investigaciones empíricas, no sólo de ciudades latinoamericanas sino de otros rincones del mundo. Por ejemplo, Pinson y Thomann (2001:114) lo muestran para el sur de Francia, concretamente en Aixen-Provence, postulando que las territorialidades periurbanas han devenido ligeras.

d. La casa hiperconectada. La entronización de la casa se viene produciendo en un contexto en el cual la vivienda — como construcción material— cada día está más conectada a distintas redes: es la casa hiperconectada, es decir, las viviendas —materialmente- están interconectadas en numerosas redes. Este fenómeno supone la posibilidad de establecer relaciones sociales remotas, precisamente por las redes que interconectan a las viviendas.

Al mismo tiempo, la casa se "desconecta" de la socialidad, así como de las interacciones y copresencias, de los mundos circundantes. Las casas hiperconectadas se constituyen en casas aisladas de muchas de las formas básicas de socialidad. Indudablemente esto no es ajeno al individualismo urbano contemporáneo (Bourdin, 2005), aunque también es necesario reconocer que forma parte de una particular dimensión del individualismo, más asociada al aislamiento en la hiperconexión que a la dimensión egoísta del individualismo.

e. La desaparición de la noción de vecindario. Muy relacionado con lo anterior, aparece como un emergente la "obsolescencia" del concepto "vecindario". Hay 
vecinos, pero no vecindario entendido como el entorno de socialidad inmediata. La desaparición del vecindario trae consigo la disolución de una trama de relaciones sociales, que no necesariamente eran profundas pero existían. Paradójicamente, perdura el vecino como actor social, pero al no ser parte de esa trama llamada vecindario, este sujeto se redefine en tanto la persona que reside de manera próxima o inmediata exclusivamente en términos de distancia física. En nuestras propias investigaciones empíricas sobre la periferia excluida del oriente de la ciudad de México, hemos encontrado que aun en condiciones de pobreza urbana se da el debilitamiento de la noción de vecindario (Lindón, 1999). Por cierto, son situaciones muy lejanas a las supuestas relaciones de solidaridad de los pobres de la ciudad postuladas por numerosas investigaciones urbanas de los años setenta.

Entonces, el proceso al que asistimos es que la casa, lejos de ser la base para la construcción de esos vínculos sociales entre desconocidos, es decir, para construir la ciudad y la vida urbana por proximidades entre las casas y sus habitantes, por densificación, se constituye hoy en día en la avanzada de la "no ciudad", o en la expresión de una forma territorial para la cual aún no hemos encontrado una voz adecuada para nombrarla. Seguramente que las voces suburbio, periferia, ciudad difusa, ciudad dispersa, ciudad in-urbana, no son las mejores porque más que plantear un contenido a partir de lo que son estas formas socio-espaciales, lo inducen en contraste con "la ciudad".

Un rasgo propio es que esta forma de "no ciudad" se da en condiciones de proximidades físicas, lo que es relevante si se tiene en cuenta que en otros momentos históricos la proximidad física era la pauta para la conformación de lo urbano. Posiblemente, el fenómeno pueda ser considerado como una fase avanzada de la suburbanización. Aquél transformó la ciudad, más aún cuando se extendió y reprodujo ad infinitum, llegando a la paradoja que planteara Cynthia Ghorra-Gobin (2002):
En algunas ciudades, como Los Ángeles, "todo se tornó suburbio"; cuando en esencia hasta la voz suburbio indica el territorio que está más allá de la urbe. Sin embargo, en el suburbio todavía había un concepto de vecindario, superficial y frágil, pero existía. Esa noción de vecindario al ampliarse se conectaba con la noción de espacio público; en estos ambientes se jugaba buena parte de lo urbano.

Mucho se ha insistido sobre la heterogeneidad de las ciudades actuales, incluso en términos culturales y étnicos, con todo lo que los procesos migratorios contribuyen a ello. Sin embargo, tal vez no ha sido igualmente estudiado el tema de las temporalidades más largas que requieren los habitantes de la ciudad para aceptar y hacer suyas esas heterogeneidades. Posiblemente, esas temporalidades más largas permitan comprender el sentido de hostilidad con el que se percibe el medio urbano respecto al "otro" diferente que lo habita. Esto no es sólo un fenómeno psicosocial. La disminución en la exposición al medio urbano también contribuye a un fenómeno que podríamos denominar "desaprendizaje" de la interacción social en la ciudad, es decir, de las formas clásicas de convivencia urbana. Como dice Pesci, en la sociedad suburbana dislocada "se huye de la ciudad histórica para evitar el contacto imprevisto con los otros" (1985:65), sustituyendo aquel tipo de ciudad por un conjunto de sujetos aislados, que cuando se encuentran no saben convivir porque lo colectivo les es ajeno.

La actual entronización de la casa lleva consigo rasgos propios de la suburbanización, pero profundiza la deconstrucción de la ciudad, el individualismo y, más aún, el aislamiento. La entronización de la casa, y su construcción social como búnker, significa que se deja de ser habitante de una ciudad con un punto de referencia que es la casa, para constituirse en habitante de una casa que está dentro de una ciudad difusa, fragmentada, segregada y rechazada. Habitar una casa y no una ciudad, por la que sólo se circula fatigadamente, 
implica una reducción y enrarecimiento de la socialidad hasta niveles críticos, así como cancelar lo desconocido e imprevisto, que en las ciudades ha sido lo propio de la cotidianidad. Un ejemplo muy ilustrativo de esta problemática se puede encontrar en Sylvia Ostrowetsky cuando plantea que "nuestra relación con el espacio público es casi esquizofrénica” (2001:152), ya que más allá de algunos pocos momentos en la calle, es en el aislamiento del hogar individual en donde se manifiesta el espacio público: en las imágenes de la televisión, en la lectura del periódico...

\section{Reflexiones finales}

Desde el inicio hemos planteado la hibridación de modelos de vida urbana. Este fenómeno de la construcción social de la casa búnker a expensas de la vida urbana, en las ciudades mexicanas, y en la ciudad de México en particular, se presenta de manera bastante nítida en algunos casos, aunque en otros aún resulta algo muy remoto. Eso es parte de la mencionada hibridación. En otras palabras, la construcción social de la casa búnker marca un horizonte esbozado e instaurado a veces, lejano otras aunque factible. Seguramente no es el único horizonte para la casa, la ciudad y la vida urbana.

Asimismo, queremos insistir en que en este fenómeno han desempeñado un papel muy importante las clases medias urbanas por su apertura a estos modos de vida suburbanos. Con la peculiaridad de que esta apertura clasemediera ha sido retomada por los urbanizadores y promotores inmobiliarios y ofrecida repetidas veces como un "producto" también para otros grupos sociales. De modo tal que lo que originalmente era característico de las clases medias urbanas, cada vez parece haber arraigado en más grupos de la estructura social. Incluso, lo hemos planteado en otros trabajos, en los grupos urbanos más desfavorecidos de la periferia de la ciudad de México hay muchos elementos de este modelo suburbano que se han filtrado en su cotidianidad, aun en la pobreza. En estos casos el modelo suburbano americano se presenta de manera muy nítida en el ámbito de las "aspiraciones", aun cuando no haya sido alcanzado materialmente. Una paradoja de esta hibridación territorial radica en que las aspiraciones y la subjetividad espacial se viven desde nociones como el mito de la casa propia y la vida suburbana, al mismo tiempo ocurre que, tanto material como económicamente, se suele vivir en la pobreza aislada y fragmentada de la que hablaban autores como Milton Santos.

Algo que también resulta relevante es que si esta construcción social de la casa búnker no sólo ha florecido entre las clases medias y en los barrios y fraccionamientos cerrados, en términos territoriales, las condiciones materiales para que arraigue esta construcción de sentido se reproducen en casi toda la ciudad. Circunstancias particulares como los procesos de renovación urbana de áreas más o menos centrales, contribuyen a que las nuevas construcciones de estas zonas de la ciudad también se realicen como para favorecer el modelo de la casa búnker. De esta forma, la tendencia parece particularmente notable por presentarse en diversos grupos sociales y en diversas zonas de la ciudad.

Para los estudiosos de la ciudad, estos fenómenos implican un desafío ya que requieren métodos y estrategias de acercamiento a la realidad, sensibilizadores de lo que está en juego. En este sentido, una cuestión decisiva es la escala de análisis, otra es la apertura a la subjetividad social y espacial y, sobre todo, el punto de vista del habitante.

Indudablemente, esto implica que no siempre se puede comprender la ciudad solamente con la mirada alejada y desde arriba, o bien, otorgándole la voz a aquellos actores que tienen capacidad de decisión política. Quienes en la actualidad analizan la ciudad dispersa/difusa han planteado el fin del espacio público, 
pero por la propia escala de análisis, lo más usual es que estos análisis no se atrevan a penetrar en el estudio de los espacios domésticos, como por ejemplo la casa. Por eso, en estas reflexiones también nos interesa destacar tal estrategia metodológica, que consiste en penetrar en los espacios domésticos, pero sin desvincular los espacios interiores de los procesos extensos que florecen en los espacios exteriores, como es el caso de la difusión de la ciudad en el territorio sin límites.

\section{Notas}

${ }^{1}$ En otra ocasión hemos analizado con cierto detenimiento la diferencia entre ambas expresiones. De manera muy sintética podemos comentar que se puede reservar la expresión "suburbio" para aquellos procesos que recrean el modelo americano suburbano, esencialmente de la clase media, de casas propias individuales y ocupadas por familias nucleares. En tanto que reservamos la expresión periferia para los procesos más difundidos en ciertos entornos de las ciudades latinoamericanas, en los cuales los grupos sociales excluidos de la vivienda resuelven, a través de la autoconstrucción, el acceso a la vivienda en mercados de suelo urbano irregulares (Hiernaux y Lindón, 2004a).

${ }^{2}$ Cabe subrayar que este trabajo pretende aportar una mirada desde la complejidad propia de las sociedades urbanas actuales, en este caso orientada a la comprensión de ciertos procesos urbanos. Por lo mismo, las líneas de fuerza que se van dibujando no deberían ser interpretadas con esquemas simples, como los de relaciones causa-efecto. Más que entender este fenómeno de la entronización de la casa, como una consecuencia, lo vemos como una particular configuración en la que convergen múltiples elementos y todo ello dentro de una peculiar historicidad.

${ }^{3}$ El mismo Soja menciona algunos de estos neologismos: "ciudades exteriores", "ciudades marginales", "tecnópolis", "tecnoburbios" "paisajes de silicona", "possuburbios", "metroplexos" (2004: 116). Asimismo, a título ilustrativo, cabe citar algunas de estas expresiones en su versión original inglesa: "suburban business districts; major diversified centers; suburban cores; minicities; suburban activity centers; cities of realms; galactic cities; urban subcenters; pepperonipizza cities; superburbia; technoburbs; nucleations; disurbs; service cities; perimeter cities; peripheral centers, urban villages".

${ }^{4}$ Dematteis plantea el desarrollo de redes o retículas policéntricas, sobre todo, basándose en la experiencia de la región metropolitana de Milán.

${ }^{5}$ Para Stéfano Boeri, la ciudad difusa implica reconocer la ausencia progresiva de las condiciones urbanas tradicionales, como la continuidad espacial y las relaciones funcionales, por ejemplo: la relación trabajo-residencia.

${ }^{6}$ En reiteradas ocasiones los análisis sobre el modo de vida americano y la circulación internacional de sus imágenes han señalado que una de las películas más o menos recientes que presenta claramente este fenómeno es Belleza Americana, de 1999, del director inglés Sam Mendes.

${ }^{7}$ No obstante, más adelante, en algunas ocasiones usamos la expresión "vivienda", cuando lo hacemos estrictamente como referencia a la construcción material.

${ }^{8}$ En la segunda mitad del siglo XX, en la medida en que los estudios urbanos se fueron desarrollando, ampliando y diversificando, también fue notorio que el análisis de la ciudad se distanció crecientemente del análisis de "la casa", que fue quedando más bien como un problema del arquitecto. Sin embargo, con anterioridad, se pueden encontrar visiones más humanistas, en las cuales el estudio de la espacialidad incluía expresamente la consideración de la casa. Por ejemplo, en las primeras décadas del siglo XX los geógrafos franceses vidalianos estudiaban la casa como una escala de análisis de la relación del ser humano con el medio geográfico. Desde esta perspectiva se pueden recordar los estudios de Albert Demangeon (1920) y Pierre Deffontaines (Deffontaines y Durliat, 1958). No obstante, en aquel tiempo el análisis de la casa privilegiaba cuestiones relacionadas con su materialidad, como los materiales de construcción. El distanciamiento de la casa que se observa en los estudios urbanos de las últimas décadas del siglo XX posiblemente sea una muestra del desinterés por las escalas urbanas más próximas a la persona, lo que, en última instancia, lleva a miradas no humanísticas.

${ }^{9}$ Es importante destacar que empleamos la expresión "patrimonialista" en la perspectiva individual. Por ello, se relaciona con la conocida aspiración de "tener una casa propia". Ese es el patrimonio al que hace referencia nuestra expresión. Desde una perspectiva semejante, Jacques Lévy habla de la "patrimonialización" en referencia con la periurbanización de Aix-en-Provence (2001: 7). Esta observación es necesaria ya que en los estudios urbanos también es frecuente el uso de la expresión "patrimonialismo", en el sentido de la 
preservación del patrimonio histórico de las ciudades. Incluso, algunos autores -como Daniel Hiernaux- han planteado la existencia de "imaginarios urbanos patrimonialistas" que intervienen en los procesos de renovación de los centros históricos (Hiernaux, 2006). Pero, en esos casos, no se trata de concepciones individualistas, como las consideradas en nuestro trabajo, sino perspectivas de tipo colectivista.

${ }^{10}$ Por ejemplo, la "huida a la interioridad" planteada por Lukács a inicios del siglo XX, en su versión de la tragedia de la cultura (1985).

${ }^{11}$ Tuan ha analizado en diversas ocasiones el concepto "Wilderness", incluso ha revisado el sentido que ha tomado en distintas tradiciones religiosas y en distintos momentos históricos. Y concluye que no puede ser definido objetivamente porque es tanto un estado del espíritu como una descripción de un orden natural frente al cual el ser humano experimenta admiración y respeto (1990: 112).

${ }^{12} \mathrm{El}$ tema de la fugacidad viene generando creciente interés para el análisis de la vida metropolitana. Desde esta perspectiva la mayor parte de los análisis consideran la fugacidad exclusivamente en términos temporales. $\mathrm{Al}$ respecto, cabe recordar los trabajos de Daniel Hiernaux por realizar un tratamiento de la fugacidad en el cual el análisis no se limita a la temporalidad, sino que enfatiza la espacialidad (Hiernaux, en prensa).

${ }^{13}$ Se puede recordar que Henri Lefebvre ya había planteado a fines de los años sesenta que las ciudades de la modernidad ya no se habitan, sino se circulan (1984: 128).

\section{Bibliografía}

Allen, Barbara, 2003, "Les relations entre le dedans et le dehors. La construction du sens de chez soi dans les quartiers d'habitat social', en Béatrice Collignon, y JeanFrançois Staszak (dir.), Espaces domestiques: Construire, habiter, représenter, BREAL, Paris, pp. 137-148.

Bachelard, Gaston, 1992, La poética del espacio, Fondo de Cultura Económica, Col. Breviarios, núm. 183., primera edición en francés 1957, Buenos Aires, p. 281.

Berry, Brian, 1976, Urbanization and Counterurbanization, Arnold, New York.

Boeri, Stefano et al., 1993, Il Territorio che cambia. Ambiente, paessagi e immagini della regione milanese, Ed. Abitare, Milán.
-, 2000, Mutaciones, Ed. ACTAR, Barcelona.

Bourdin, Alain, 2005, La métropole des individus, Editions de l'Aube, Paris.

Cabrales Barajas, Luis Felipe (ed.), 2002 Latinoamérica: Países abiertos, ciudades cerradas, Universidad de GuadalajaraunESCO, Guadalajara.

Collignon, Béatrice y Jean-François Staszak (dirs.), 2003, Espaces domestiques: Construire, habiter, représenter, BREAL, Paris.

Contamine, Philippe, 1990, "Las instalaciones del espacio privado, siglo XIV-XV", en Georges Duby y Philippe Ariès (dir.), Historia de la vida privada: El individuo en la Europa feudal, vol. 4, Taurus, Madrid.

Deffontaines, Pierre y Marcel Durliat, 1958, Presentación de la España del Este, Editorial Juventud, primera edición en francés 1957, Barcelona.

Demangeon, Albert, 1920, "L'habitation rurale en France. Essai de classification des principaux types", en Annales de Géographie, pp. 352-375.

Dematteis, Giuseppe (1995), Progetto Implicito, Edit. F. Angeli, Milán.

—1998, "Suburbanización y periurbanización: Ciudades anglosajonas y ciudades latinas", en Francisco Javier Monclús (ed.), La ciudad dispersa, Centre de Cultura Contemporania de Barcelona, Barcelona, pp. 17-33.

Garreau, Joel, 1991, Edge City: Life on the New Frontier, Doubleday, New York.

Ghorra-Gobin, Cynthia, 2002, Los Angeles: Le mythe américain inachevé, CNRS, Coll. CNRs Plus, primera edición en francés 1997, Paris

—, 2003, Villes et société urbaine aux États Unis, Armand Colin, Paris.

Goffman, Erving, 1991, "La ritualización de la femineidad", en Los momentos y sus hombres, textos seleccionados y presentados por Yves Winkin, Paidós, primera edición en inglés 1976, Barcelona, pp. 135-167.

Hiernaux, Daniel, 2006, “Los centros históricos: ¿espacios posmodernos?: De choques de imaginarios y otros conflictos", en Alicia Lindón, Miguel Ángel Aguilar y Daniel Hiernaux (coords.), Lugares e Imaginarios en las Metrópolis, Anthropos-uam, Barcelona, pp. 27-42.

-, en prensa, "Geografía de los tiempos y de los espacios efímeros y fugaces", en Joan Romero y Joan Nogué (coords.), Las otras geografías, Ed. Tirant Lo Blanch, Barcelona. 
Hiernaux, Daniel y Alicia Lindón, 2004a, “La periferia: voz y sentido en los estudios urbanos", en Papeles de Población, Universidad Autónoma del Estado de México, núm. 42, octubre-diciembre, México, pp. 103-129.

Hiernaux, Daniel y Alicia Lindón, 2004b, "Repensar la periferia: de la voz a las visiones exo y egocéntricas", en Adrián Guillermo Aguilar (coord.), Procesos Metropolitanos y Grandes Ciudades, Dinámicas recientes en México y otros países, Instituto de Geografía, PUEC, CRIM-UNAM, CONACYT, Ed. Miguel Ángel Porrúa, Colección Conocer para Decidir, México, pp. 413-443.

Kowarick, Lucio (ed.), 1994, Social Struggles and the City: The Case of Sao Paulo, Monthly Review Press, New York.

Lefebvre, Henri, 1984, La vida cotidiana en el mundo moderno, Alianza Editorial, primera edición en francés 1968, Madrid.

Lévy, Jacques, 2001, "Préface: Habiter l'espace avec, sans, contre les autres", en Daniel Pinson y Sandra Thomann, La maison en ses territoires: De la villa à la ville diffuse, L'Harmattan, Paris.

Lindón, Alicia, 1999, De la trama de la vida cotidiana a los modos de vida urbanos, El Colegio de México-El Colegio Mexiquense, México.

—, 2003, "La precariedad laboral como experiencia a través de la narrativa de vida", en Gaceta Laboral, vol. 9, marzo, 2003, Centro de Investigaciones y Estudios Laborales y de Disciplinas Afines, Universidad de Zulia, Venezuela, pp. 333-352.

—, 2005a, "El mito de la casa propia y las formas de habitar", en SCRIPTA NOVA, Revista Electrónica de Geografía y Ciencias Sociales, vol. IX, núm. 194, 1 de agosto, Universidad de Barcelona, Barcelona.

—, 2005b, "Figuras de la territorialidad en la periferia metropolitana: Topofilias y topofobias", en Rossana Reguillo y Marcial Godoy Anativia (coords.), Ciudades Translocales: Espacios, Flujo, Representación. Perspectivas desde las Américas, Social Science Research Council-ITEso, Guadalajara, pp. 145-172.

—, 2005c, "La construcción social de los paisajes invisibles y del miedo", en III' Seminario Internacional sobre Paisaje: Paisajes incógnitos, territorios ocultos: Las geografías de la invisibilidad, 20 a 22 de octubre de 2005, Catalunya, uimPCentro Ernest Lluch, Olot. URL: http:// www.catpais atge.net/cat/documentacio _seminari2005.php, visitado: 28 septiembre 2006.

—, 2006a, "La construcción social de paisajes invisibles y del miedo", en Joan Nogué (ed.), La construcción social del paisaje, Ed. Biblioteca Nueva, Colección Teoría y Paisaje, Madrid, pp. 213-236.

—, 2006b, "Del suburbio como paraíso a la espacialidad periférica del miedo", en Alicia Lindón, Miguel Ángel Aguilar y Daniel Hiernaux (coords.), Lugares e Imaginarios en las Metrópolis, Anthropos-uam, Barcelona, pp. 85-106.

López Lévi, Liliana; Eloy Méndez Saínz e Isabel Rodríguez Chumillas, 2006, "Fraccionamientos Cerrados, Mundos Imaginarios", en Alicia Lindón, Miguel Ángel Aguilar y Daniel Hiernaux (coords.), Lugares e Imaginarios en las Metrópolis, Anthropos-UAm, Barcelona, pp. 161-170.

Lukács, Georg, 1985, El alma y las formas/Teoría de la novela, Grijalbo, México.

Lynch, Kevin, 1998, La imagen de la ciudad, Gustavo Gili, primera edición en inglés 1960, Barcelona.

Monclús, Francisco Javier, 1998, "Suburbanización y nuevas periferias. Perspectivas geográfico-urbanísticas", en Francisco Javier Monclús (ed.), La ciudad dispersa, Centre de Cultura Contemporania de Barcelona, Barcelona, pp. 5-15.

Nel.lo, Oriol, 1998, "Los confines de la ciudad sin confines. Estructura urbana y límites administrativos en la ciudad difusa", en Francisco Javier Monclús (ed.), La ciudad dispersa. Centre de Cultura Contemporania de Barcelona, Barcelona, pp. 35-57.

Nel.lo, Oriol y Francesc Muñoz, 2004, "El proceso de urbanización”, en Juan Romero (coord.), Geografía Humana, Ed. Ariel, Barcelona, pp. 255-332.

Ostrowetsky, Sylvia, 2001, "Les transformations de l'espace public", en Sylvia Ostrowetsky (ed.), Lugares, d'un continent l'autre: Perception et production des espaces public, L'Harmattan, Paris, pp. 139-158.

—, 2001, "Introduction", en Sylvia Ostrowetsky (ed.), Lugares, d'un continent l'autre: Perception et production des espaces publics, L'Harmattan, Paris, pp. 7-24.

Pesci, Rubén, 1985, La ciudad in-urbana, CEPA, La Plata.

Pinson, Daniel y Sandra Thomann, 2001, La maison en ses territoires: De la villa à la ville diffuse, L'Harmattan, Paris.

Sachs-Jeantet, Céline, 1993, "La citoyenneté, projet de civilisation urbaine", en Un autre partage: homme, ville, natur, Erès y unESCO, Toulouse, pp. 173-198.

-, 1994, Humaniser la ville. Les enjeux de la citoyenneté et de l'urbanité, Independent Commission for Population and Quality of Life, UNESCO, Paris.

Santos, Milton (1990), Metrópole Corporativa Fragmentada: O caso de Sao Paulo, Nobel-Secretaria de Estado da Cultura, Sao Paulo. 
Soja, Edward W., 2001, Postmetropolis: Critical Studies of cities and regions, Blackwell, Oxford.

—, 2004, "Por el interior de la exópolis: escenas del condado de Orange", en Michael Sorkin (ed.), Variaciones sobre un parque temático: La nueva ciudad americana y el fin del espacio público, Gustavo Gili, primera edición en inglés 1993, Barcelona, pp. 115-145.
Tuan, Yi-Fu, 1990, Topophilia: A study of environmentalperception, attitudes and values, New York, Columbia University Press, primera edición en inglés 1974, New Jersey.

Veltz, Pierre (1999), Mundialización, territorios y ciudades, Ed. Ariel, primera edición en francés 1996, Barcelona. 